\title{
The Cost of Generic Clinical Mastitis in Dairy Cows as Estimated by Using Dynamic Programming
}

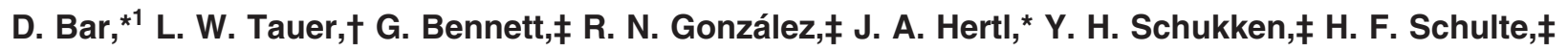 \\ F. L. Welcome, $\ddagger$ and Y. T. Gröhn* \\ *Section of Epidemiology, Department of Population Medicine and Diagnostic Sciences, College of Veterinary Medicine, \\ †Department of Applied Economics and Management, College of Agriculture and Life Sciences, and \\ $\ddagger$ Quality Milk Production Services, Department of Population Medicine and Diagnostic Sciences, College of Veterinary Medicine, \\ Cornell University, Ithaca, NY 14853
}

\begin{abstract}
The objective of this study was to estimate the cost of generic clinical mastitis (CM) in high-yielding dairy cows given optimal decisions concerning handling of CM cases. A specially structured optimization and simulation model that included a detailed representation of repeated episodes of CM was used to study the effects of various factors on the cost of CM. The basic scenario was based on data from 5 large herds in New York State. In the basic scenario, $92 \%$ of the CM cases were recommended to be treated. The average cost of CM per cow and year in these herds was $\$ 71$. The average cost of a CM case was $\$ 179$. It was composed of $\$ 115$ because of milk yield losses, $\$ 14$ because of increased mortality, and $\$ 50$ because of treatment-associated costs. The estimated cost of CM was highly dependent on cow traits: it was highest (\$403) in cows with high expected future net returns (e.g., young, high-milkyielding cows), and was lowest (\$3) in cows that were recommended to be culled for reasons other than mastitis. The cost per case of CM was $18 \%$ higher with a $20 \%$ increase in milk price and $17 \%$ lower with a $20 \%$ decrease in milk price. The cost per case of CM was affected little by a $20 \%$ change in replacement cost or pregnancy rate. Changes in $\mathrm{CM}$ incidence, however, resulted from changes in these factors, thus affecting whole-farm profitability. The detailed results obtained from this insemination and replacement optimization model can assist farmers in making CM treatment decisions.
\end{abstract}

Key words: dairy cow, clinical mastitis, cost, dynamic programming

\section{INTRODUCTION}

Low profit margins in the dairy industry provide incentives to dairy producers to make good economic deci-

Received August 3, 2007.

Accepted January 21, 2008.

${ }^{1}$ Corresponding author: db324@cornell.edu sions in general and apply sound economic disease management decisions in particular. To achieve this, relevant estimations about disease costs have to be determined. These estimations can then be used in evaluating the benefits of applying preventive measurements to decrease disease incidence, disease losses, or both, and in the process allow the evaluation of individual cow disease treatment options. Static models have limited usefulness in estimating disease costs given the dynamics of the cow herd; dynamic models that permit modeling herd dynamics are much more appropriate (Seegers et al., 2003). Such dynamic models have been developed and used to address herd replacement decisions. Using a dynamic programming (DP) model, De Vries (2006) estimated the retention pay off (RPO) of open and pregnant cows that were identical in other traits. The difference was therefore the value of pregnancy in specific cows. The price of pregnancy was shown in this study to vary greatly among individual cows and under different herd parameters. Such dynamic models of the cost of a disease are relatively scarce; on mastitis, undoubtedly the disease with the highest economic importance, only a few have appeared in the literature. Yalcin and Stott (2000) calculated the cost-benefit of whole-herd mastitis preventive measurements by using a small DP model with a stage length of only one lactation. Their model enabled replacement of cows only at the end of the lactation, and was therefore not detailed enough to support individual cow decisions. The model of Houben et al. (1994), used for estimating the optimal handling of mastitic cows, is probably the most comprehensive animal replacement DP model reported to date. The state space of their model was nearly 7 million, representing a large amount of realistic complexity, thus providing detailed individual cow mastitis (as well as fertility and productivity) decision support. We were encouraged to repeat and extend this estimation effort for several reasons:

1. New data on the effects of mastitis suggest a different model structure than in Houben's model: the 
effect of mastitis on production (Gröhn et al., 2004) and on the risk of culling (Gröhn et al., 2005) is time dependent. The impact on milk production is high close to disease occurrence and tapers off after approximately $2 \mathrm{mo}$. Therefore, a structural change to Houben's model is warranted.

2. In Houben's model, the milk loss in the first month after clinical mastitis (CM) was assumed to be reduced by $40 \%$ in primipara and $50 \%$ in multipara. This would result in today's high-yielding dairy cow having a loss of more than $750 \mathrm{~kg}$ of milk in the first month following CM. Our estimates are considerably lower (Bar et al., 2007).

3 . The current milk production of dairy cows is approximately $4,000 \mathrm{~kg}$ more than estimated in Houben et al. (1994). In addition, there seems to be a shift in mastitis-causing agents (less contagious, more environmental) in the past $10 \mathrm{yr}$ in modern dairy herds (Makovec and Ruegg, 2003), possibly causing different effects than in Houben's estimates (Gröhn et al., 2004).

4. We have new information concerning the effects of repeated $\mathrm{CM}$ within and between lactations, indicating different DP parameters (of milk yield, culling, and transition probabilities).

The hypothesis of this study was that the cost of CM varies greatly for individual cows, depending on the performance of the cow, the lactation number, the stage of lactation, pregnancy status, prices, and breeding and replacement options. A more informed decision-making process in CM management is possible through better understanding of these relationships. By using more current knowledge and data, the objectives of this study were to estimate CM costs in relation to individual cow characteristics, to calculate expected whole-herd costs, and to relate these costs to exogenous parameters such as milk price, replacement costs, or pregnancy rates by using a newly constructed DP model.

\section{MATERIALS AND METHODS}

\section{Herds Description}

We used data from 5 dairy farms located in New York State. These farms milked an average of 1,200, 1,100, 750,650 , and 600 Holstein milking cows and were followed for approximately 24 mo (years 2004 to 2006). The rolling herd average was close to $11,000 \mathrm{~kg}$ per cow/yr on a 305-d basis (range 10,700 to 11,500); monthly mean SCC was 225,000 cells $/ \mathrm{mL}$ (monthly range, 180,000 to 355,000 ) and varied little among the 5 farms. Cows were housed in covered barns with concrete floors and free stalls. All groups of cows were fed a balanced TMR via feed alleys. Cows were milked 3 times per day. Each milking unit had milk meters capable of automatically recording milk production. Reliable data were readily available on parity, diseases, inseminations, drying off, calving, and exit from the herd, because those data were also used by herd personnel to manage the dairy herd. All milkers on the cooperating farms were familiar with detection of CM by examination of foremilk. Some cases of CM were identified by milkers (warm, swollen udder, or changes in the milk), whereas others were detected by the herdsperson examining the cows' performance. Farm personnel sampled milk for microbiological culture from quarters with signs of CM. The samples were usually collected daily and were cultured by the Quality Milk Production Services laboratories.

\section{Replacements and Inseminations Optimization and Simulation Model}

Programming Tools. Our model was built by using the Multi Level Hierarchic Markov Process (MLHMP) software (Kristensen, 2003) as the application program interface. This software has been used in building and solving various dynamic models (Kristensen and Sollested, 2004; Nielsen et al., 2004). The MLHMP software combines the properties of policy iteration and value iteration in solving the DP model. Policy iteration is fast converging for infinite time problems, but can be used only for a relatively small state space because the solution involves matrix inversion; it is used in the founder (parent) level of the Markov process. Value iteration, on the other hand, is capable of solving very large state space models for a finite time horizon, and is used in the child processes, which are of finite time horizon because no animal lives forever. Because the MLHMP software visualizes the model tree with a graphic interface along with detailed representation of the various stage-state combinations, model building and debugging are greatly facilitated. Our model was used as a plug-in into the MLHMP software, which in turn constructs the model with the plug-in specifications. The program calculates the optimal replacement and insemination policy, and Markov chain simulation following the optimal policy can then be requested to calculate estimates of whole-herd results.

Model Structure. The model was constructed as a 3-level hierarchical Markov process. The schematic structure is graphically illustrated in Figure 1. The founder (parent) level is of infinite time horizon and contains state variables that are permanent traits throughout the life span of a cow. The child level is divided into time steps (stages), each representing one whole lactation (its length is determined by the next 


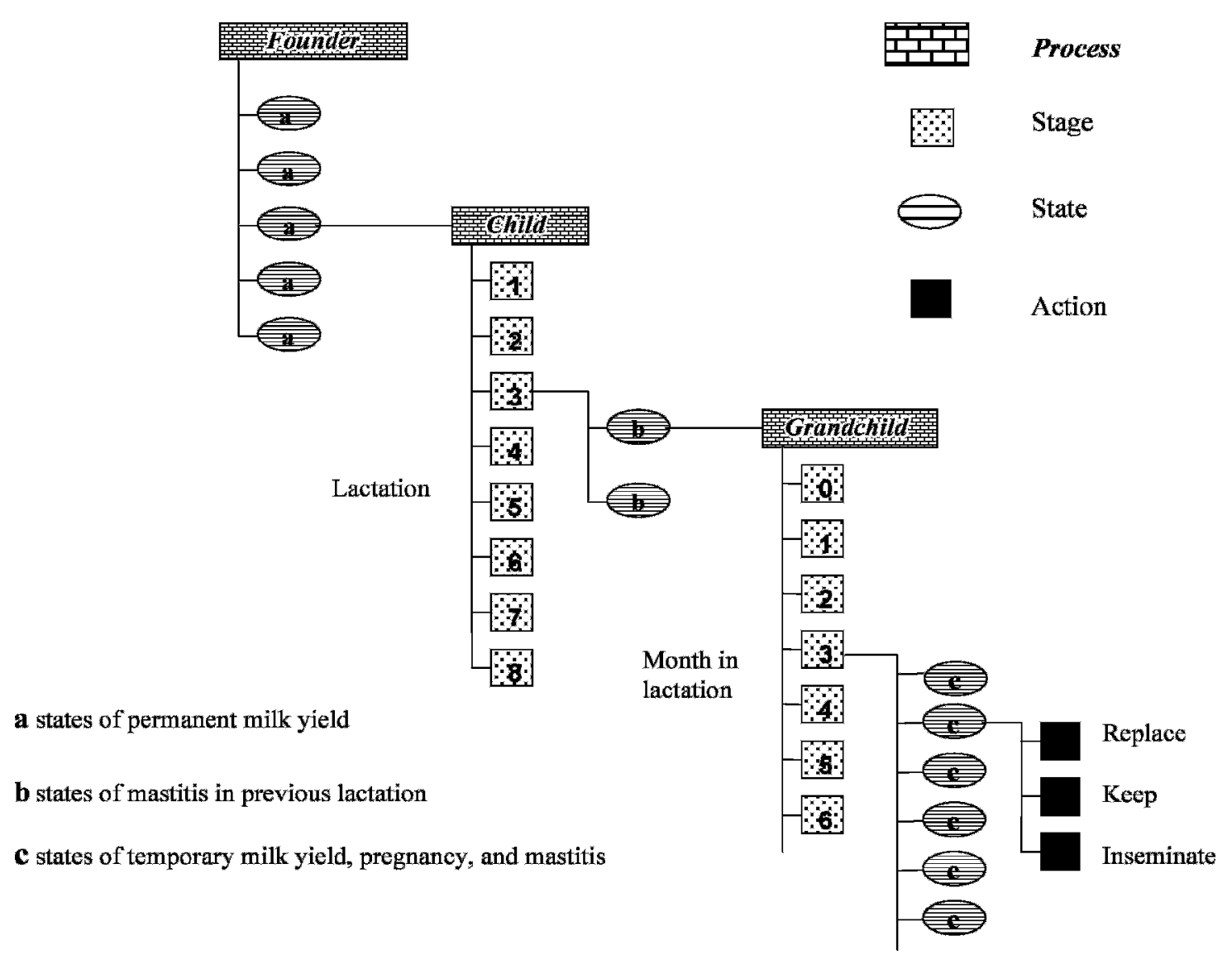

Figure 1. Schematic representation of the replacement and insemination optimization model used in this study to estimate clinical mastitis costs.

level). State variables in this second level are permanent traits throughout the lactation. The grandchild level is divided into stages of 1 mo duration. Exceptions are a short after-calving stage of $3 \mathrm{~d}$, a dry period stage of $2 \mathrm{mo}$, and a dummy stage of length zero if the cow is to be dried off (this dummy stage was necessary to enable lactations of variable lengths). State variables in this third level are permanent only for each time step. Possible actions can be taken at this level. In our model, 3 actions were possible: 1 ) replace the cow with a calving heifer; 2) keep the cow for another month without insemination (and treat the cow if she has $\mathrm{CM}$ ); or 3) inseminate the cow for another month (after the voluntary waiting period that was set to $2 \mathrm{mo}$ ).

Stage and State Variables. In the founder level (parent), 5 milk yield levels (permanent milk-producing ability) are modeled as $+5,+2.5,0,-2.5$, and $-5 \mathrm{~kg}$ from the mean level of milk production per day. In the child level, 8 possible whole-lactation stages are modeled, with 2 carryover mastitis states from the previous lactation (yes/no). In the grandchild level, 20 lactation stages are modeled (maximum calving interval of $20 \mathrm{mo}$ ) as 5 temporary milk yield levels $(+4,+2,0,-2$, and $-4 \mathrm{~kg}$ of milk per day relative to the permanent milk yield); 9 pregnancy status levels $(0=$ open, 1 to 7 mo pregnant, and $8=$ dry); one involuntarily culled state; and 13 mastitis states. The mastitis states were defined as follows: 0 = no mastitis, 1 = first occurrence of $\mathrm{CM}$ (observed at the end of the stage to enable immediate culling without treatment cost and production losses), $2,3,4$ corresponding to $1,2,3$, and more months after first $\mathrm{CM}$, respectively, 5 = second occurrence of $\mathrm{CM}$, and so forth. Clinical mastitis events after the third occurrence were modeled as again being a third CM case. After excluding most impossible combinations (e.g., 6 mo pregnant and 3 mo in lactation), the model described 560,725 stage-state combinations. The objective function maximized by the model was the discounting criterion (Kristensen, 2003), that is, maximizing the net present value of a cow, using a yearly interest rate of 8\% (De Vries, 2006).

\section{Model Parameters}

Prices. Prices for milk, beef, variable costs, fixed costs, and feed cost were taken from De Vries (2006) to 
facilitate comparison of our results with his results. Different prices would result in a different solution. In our DP model, we separated the cost of a cow kept in the herd into 2 components: a $\$ 150$ fixed cost of keeping a cow for a month regardless of production level $(7-\mathrm{kg}$ lactating ration DMI per day and all operating and fixed costs), and a $\$ 0.222$ net return $/ \mathrm{kg}$ of milk (milk price minus feed price to produce $1 \mathrm{~kg}$ of milk). This was done for modeling simplicity instead of having a separate bioeconomic module as in De Vries (2006). The full beef price ( $\$ 400)$ was assumed for cows in late lactation that were culled by model recommendation. A discount factor (range 0.8 to 1.0) was used to adjust this beef price for cows in the first $7 \mathrm{mo}$ of the lactation (because of lower BW and BCS). Cows that were forced to exit the herd (because of decisions not determined by the model) were assumed to receive $50 \%$ of the beef price at the first month after calving, and $65 \%$ afterward. This discounting was based on the ratio of cows dying on the farms and cows sold to a beef handler found in the 5 study farms (Bar, 2007).

Milk Yields. Lactation curves were estimated by using 135,166 weekly average milk yields from 10,380 lactations in the 5 study farms (Bar et al., 2007). Lactations were expressed in the DP model as the actual yields in the first $3 \mathrm{mo}$ and a constant linear negative slope afterward, because that was the functional form (at least in the first $52 \mathrm{wk}$ of the lactation) estimated in the study farms (Bar et al., 2007). Values for the first lactation were $26.3,34.4$, and $36.8 \mathrm{~kg}$ of milk per day in the first $3 \mathrm{mo}$, respectively, and a loss of $0.9 \mathrm{~kg}$ for each additional month afterward. For the second lactation, the corresponding estimates were 39.1, 47.7, 46.6 , and a negative slope of 2.25. For the third lactation, these estimates were $40.3,48.9,47.8$, and a negative slope of 2.3. A progressive penalty with lactation number beyond 3 was set to $0.75 \mathrm{~kg}$ of milk reduction per day (e.g., a cow in her fifth lactation was expected to give $1.5 \mathrm{~kg}$ less milk per day than a cow in her third lactation).

We chose to model the actual milk yield of cows in 2 separate components: the expected milk yield level (first level in the Markov process) and a deviation from this estimate (third level). Such a separation has not been considered in any previous dairy DP model. The reason for this approach was that farmers often evaluate the performance of their cows as deviations from expectations or past performance; they have some prior knowledge about the cow (from her genetic potential and previous milk yield) and they observe the current milk yield in relation to this prior knowledge. Such an estimate for a permanent milk yield potential is also given by many herd management programs and DHI centers. Situations such as higher milk loss than the estimated average because of CM were easily modeled as deviations.

Transition Probabilities. The transition between the monthly observed relative milk yield levels followed a normal distribution, with the mean equal to the permanent milk yield level and the variance estimated from the study farms. For example, the transition probabilities to the 5 temporary milk yield levels of $+4,+2$, $0,-2$, and $-4 \mathrm{~kg}$ of milk per day in the next month for a cow currently at milk level of 0 were $0.07,0.24,0.38$, 0.24 , and 0.07 , respectively; for a cow currently at level +4 , the corresponding probabilities were $0.69,0.24$, $0.06,0.01$, and 0.00 , respectively. A replacement heifer was assumed to have a permanent milk yield level following a normal distribution that would be slightly skewed to simulate the expected genetic improvement (equivalent to $100 \mathrm{~kg}$ higher 305 -d milk production per generation) of replacement animals. The variances used were taken from a mixed model with milk yield as dependent variable, a random cow effect (variance of permanent milk yield), and the error term (variance of temporary milk yield).

The probability of a cow being pregnant in a following month was set to 0.21 if a decision was made to inseminate the cow. Because we did not consider abortion in our model and our pregnancy rate was constant, we used a slightly lower rate than De Vries (2006) to reach the same proportion of cows pregnant at the end of lactation.

Exit from the Herd. In the model, a cow could leave the herd because of 2 distinct reasons: 1 ) the model recommended culling, or 2) exit from the herd from causes that were not model determined (i.e., not determined by the decision to keep or replace the cow), but forced with some probability (such an exit is commonly called "involuntary culling"). These causes included dead cows (including euthanized cows) and cows sold for slaughter because of reasons other than milk yield, pregnancy, and mastitis (e.g., injuries, calving diseases, and lameness). The risks of forced exit were calculated from 16,145 lactations in the study farms (Bar, 2007). In the DP model they were slightly simplified as a constant monthly risk of $0.006,0.01,0.02,0.03,0.04,0.05,0.06$, and 0.07 for the first, second, third, fourth, fifth, sixth, seventh, and eighth lactation, respectively. A mortality of $2 \%$ was added in the after-calving stage (first $3 \mathrm{~d}$ after calving).

Effects of Clinical Mastitis. The effects of CM were calculated from the 5 study farms. The milk losses associated with repeated cases of CM are detailed in Bar et al. (2007) and are summarized in Table 1 as the milk loss in the first month, the second month, and the third month and later after CM. The mortalities associated with CM were calculated from 16,145 lactations in the 
Table 1. Milk loss $(\mathrm{kg})$ from generic clinical mastitis $(\mathrm{CM})$ cases $^{1}$

\begin{tabular}{lcccc}
\hline Parity & Days & First CM & Second CM & Third CM \\
\hline 1 & $0-30$ & 116 & 137 & 137 \\
& $31-60$ & 67 & 76 & 76 \\
& $\geq 61^{2}$ & 64 & 24 & 24 \\
$2+$ & $0-30$ & 183 & 186 & 162 \\
& $31-60$ & 92 & 73 & 76 \\
& $\geq 61$ & 73 & 43 & 52 \\
\hline
\end{tabular}

${ }^{1}$ Source: Bar (2007).

${ }^{2}$ Milk loss permanent during the entire later part of the lactation.

study farms (Bar, 2007). In the DP model, they were simplified as $1 \%$ mortality in primiparous cows and $2 \%$ in multiparous cows. A decision to treat the $\mathrm{CM}$ cow was associated with a cost of $\$ 50$. This cost was an estimated average caused by drugs $(\$ 20)$, the decreased value of $5 \mathrm{~d}$ worth of discarded milk from an average production cow $(\$ 20)$, and extra labor $(\$ 10)$. The monthly risks of CM used in the DP model are summarized in Table 2. These were a slight simplification of the estimates obtained from the study farms (Bar, 2007). In that study, the odds ratio of a cow that had $\mathrm{CM}$ in her previous lactation of again experiencing a CM case was very high (approximately 10); we chose to use 5 in the DP model, because we believed it should not be higher than the risk of the reoccurrence within the same lactation.

\section{Methodology of Estimating CM Cost}

Average Cost of CM in the Herd. The average net returns per cow per year for a herd without CM were

Table 2. Monthly risks (conditional probabilities) for generic clinical mastitis (CM) occurrence in the dynamic programming model, estimated from 16,145 lactations in 5 New York State dairy herds ${ }^{1}$

\begin{tabular}{ccccc}
\hline Parity & Days $^{2}$ & First CM & Second CM & Third CM \\
\hline 1 & $0-30$ & 0.03 & 0.05 & 0.09 \\
& $31-60$ & 0.01 & 0.02 & 0.08 \\
& $61-91$ & 0.01 & 0.02 & 0.04 \\
& $>91$ & 0.01 & 0.02 & 0.03 \\
2 & $0-30$ & 0.04 & 0.09 & 0.12 \\
& $31-60$ & 0.02 & 0.07 & 0.10 \\
& $61-91$ & 0.02 & 0.04 & 0.08 \\
& $>91$ & 0.02 & 0.04 & 0.07 \\
3 & $0-30$ & 0.05 & 0.10 & 0.14 \\
& $31-60$ & 0.03 & 0.08 & 0.12 \\
& $61-91$ & 0.03 & 0.05 & 0.09 \\
& $>91$ & 0.03 & 0.05 & 0.08 \\
$4+$ & $0-30$ & 0.06 & 0.12 & 0.16 \\
& $31-60$ & 0.04 & 0.10 & 0.14 \\
& $61-91$ & 0.04 & 0.06 & 0.10 \\
& $>91$ & 0.04 & 0.06 & 0.09 \\
\hline
\end{tabular}

\footnotetext{
${ }^{1}$ Source: Bar (2007).

${ }^{2}$ Days after calving for the first CM case; days after previous CM for repeated CM cases.
}

compared with the average net returns for a herd with the same parameters but with the given CM risk. The profit loss was then divided by the model-simulated CM incidence to get the herd average cost per one CM case. It is important to realize that this is a lower bound estimate of the cost of CM because the model minimizes the cost of CM under optimal treatment decisions. Actual farm experiences may differ from this optimum.

Cost of CM in Individual Cows. The RPO (given the optimal breeding and replacement policy) of 2 cows that are categorized similarly but that differ in CM status were compared to get the estimated cost of a CM case.

\section{RESULTS}

\section{Components of CM Costs}

The simulated herd results before and after assigning the milk loss in the current lactation, the expected milk loss into the next lactation, the increased mortality, and the assigned treatment cost in the DP model are detailed in Table 3 . The average cost of CM in our study herds was $\$ 71$ per cow and year ( $\$ 426$ to $\$ 355)$ and $\$ 179$ per CM case ( $\$ 71 / 0.397)$. It was composed of $\$ 115$ because of milk loss, $\$ 14$ because of increased mortality, and $\$ 50$ because of treatment-associated costs. In the basic scenario, $92 \%$ of the $\mathrm{CM}$ cases were recommended to be treated (i.e., in $8 \%$ of the cases, the recommended policy was not to treat and to cull the cow immediately).

With each CM effect added to the model, whole-herd profitability and herd life were reduced. The percentage of $\mathrm{CM}$ cases treated (i.e., that were recommended to be kept in the herd) was lower with the added CM effects.

\section{Exogenous Factors Affecting CM Cost}

The cost of CM is dependent on exogenous factors (Table 4). A higher milk price is associated with a higher $\mathrm{CM}$ cost. The cost per case of CM was $18 \%$ higher with a $20 \%$ increase in milk price and $17 \%$ lower with a $20 \%$ decrease in milk price. A higher milk price increased culling rate, increased culling of CM cows, and decreased CM incidence as a result. A lower replacement heifer price changed the cost per CM case only slightly, but the effect of $\mathrm{CM}$ on whole-herd profitability decreased because the incidence of $\mathrm{CM}$ was reduced substantially through a higher replacement rate. Moderate changes in pregnancy rate changed the cost per $\mathrm{CM}$ case very little, but had a moderate effect on $\mathrm{CM}$ incidence. Higher pregnancy rate resulted in higher CM incidence.

\section{RPO of Open Healthy and CM Cows}

The RPO of example cows (third lactation, open, with average expected and observed milk yield) either with 
Table 3. Simulated whole-herd parameters as a result of assigning the effects of clinical mastitis (CM) sequentially to the optimization and simulation model

\begin{tabular}{|c|c|c|c|c|c|c|c|c|}
\hline Item & $\underset{\$}{\text { Neturn }},^{1}$ & $\begin{array}{l}\text { Milk } \\
\text { yield }^{2}\end{array}$ & $\begin{array}{l}\text { Forced } \\
\text { exit }^{3}\end{array}$ & $\begin{array}{c}\text { Model } \\
\text { exit }^{4}\end{array}$ & $\begin{array}{l}\text { Herd } \\
\text { life }^{5}\end{array}$ & $\begin{array}{c}\text { CM } \\
\text { cases }^{6}\end{array}$ & $\begin{array}{c}\text { CM } \\
\text { treated, }{ }^{7} \\
\%\end{array}$ & $\begin{array}{c}\text { Cost } \\
\text { per } \\
\text { case }^{8}\end{array}$ \\
\hline & \multicolumn{8}{|c|}{ No CM in the model } \\
\hline & 426 & 11,565 & 19.0 & 14.4 & 36.7 & 0.0 & 0.0 & 0 \\
\hline & \multicolumn{8}{|c|}{ - Sequential changes to the model and resultant cumulative impacts of each change } \\
\hline Milk loss in the current lactation & 393 & 11,442 & 18.5 & 15.5 & 35.9 & 43.0 & 96.2 & 77 \\
\hline \multicolumn{9}{|c|}{ Combined impact of CM compared with no CM under optimal decisions } \\
\hline & -71 & -141 & -0.7 & +2.9 & -2.3 & & & 179 \\
\hline
\end{tabular}

\footnotetext{
${ }^{1}$ Net returns in US dollars per cow and year.

${ }^{2}$ Kilograms of milk per cow and year.

${ }^{3}$ Annual exit (\%) from the herd from causes that were not model determined.

${ }^{4}$ Annual exit (\%) from model-recommended culling.

${ }^{5}$ Average herd life (from first calving to exit from the herd) in months.

${ }^{6}$ Incidence of CM (cases per 100 cow years).

${ }^{7}$ Percentage of treated CM cows per CM cows.

${ }^{8}$ Average cost per CM case following an optimal replacement policy.
}

$\mathrm{CM}$ in the current month or free of CM until the current month, as a function of month after calving, are presented in Figure 2. The best policy recommended by the model is also presented in this graph. The RPO of these cows decreased from $\$ 1,060$ and $\$ 755$, respectively, at calving to a value under $\$ 0$ (at 12 mo for CMfree cows, and 8 mo for cows with $\mathrm{CM}$ ). A negative RPO means that cows were recommended to be culled. The cost of CM in these cows was therefore $\$ 305$ ( $\$ 1,060$ $\$ 755$ ) at calving, $\$ 236$ at 6 mo after calving, and close to zero if $\mathrm{CM}$ occurred a year after calving (because the cow was recommended to be culled anyway). The cost of $\mathrm{CM}$ in cows that were recommended to be culled even if they had not been affected was higher than zero because the cow could die before she was shipped. Because CM increases mortality, it has a cost even in this case.

\section{Endogenous Factors Affecting CM Cost}

The cost of CM was dependent on other endogenous factors such as the pregnancy status of the cow or her

Table 4. The effects of changes in milk price, replacement heifer cost, and pregnancy rates on wholeherd dynamics obtained by probabilistic Markov chain simulation following an optimal insemination and replacement policy

\begin{tabular}{lcccccccc}
\hline & $\begin{array}{c}\text { Net } \\
\text { return, } \\
\$\end{array}$ & $\begin{array}{c}\text { Milk } \\
\text { yield }^{2}\end{array}$ & $\begin{array}{c}\text { Forced } \\
\text { exit }^{3}\end{array}$ & $\begin{array}{c}\text { Model } \\
\text { exit }^{4}\end{array}$ & $\begin{array}{c}\text { Total } \\
\text { exit }\end{array}$ & $\begin{array}{c}\text { CM } \\
\text { cases }^{5}\end{array}$ & $\begin{array}{c}\text { CM } \\
\text { treated, } \\
\%\end{array}$ & $\begin{array}{c}\text { Cost } \\
\text { per } \\
\text { case }^{7}\end{array}$ \\
\hline Basic scenario & 355 & 11,424 & 18.3 & 17.3 & 35.6 & 39.7 & 91.9 & 179 \\
Milk price +20\% & 1,048 & 11,564 & 17.6 & 21.4 & 39.0 & 37.8 & 90.2 & 212 \\
Milk price-20\% & -330 & 11,284 & 19.3 & 13.6 & 32.9 & 42.3 & 94.0 & 149 \\
Replacement cost +20\% & 242 & 11,283 & 19.5 & 13.4 & 32.9 & 42.6 & 94.5 & 183 \\
Replacement cost -20\% & 482 & 11,653 & 16.8 & 24.9 & 41.7 & 35.7 & 87.9 & 179 \\
Pregnancy rate +20\% & 387 & 11,445 & 19.2 & 14.6 & 33.8 & 41.7 & 92.3 & 177 \\
Pregnancy rate -20\% & 309 & 11,403 & 17.1 & 21.3 & 38.4 & 36.9 & 91.1 & 182 \\
\hline
\end{tabular}

${ }^{1}$ Net returns in US dollars per cow and year.

${ }^{2}$ Kilograms of milk per cow and year.

${ }^{3}$ Annual exit (\%) from the herd from causes that were not model determined.

${ }^{4}$ Annual exit (\%) from model-recommended culling.

${ }^{5}$ Incidence of clinical mastitis (CM; cases per 100 cows and year).

${ }^{6}$ Percentage of treated CM cows per CM cows.

${ }^{7}$ Average cost per CM case following an optimal replacement policy. 


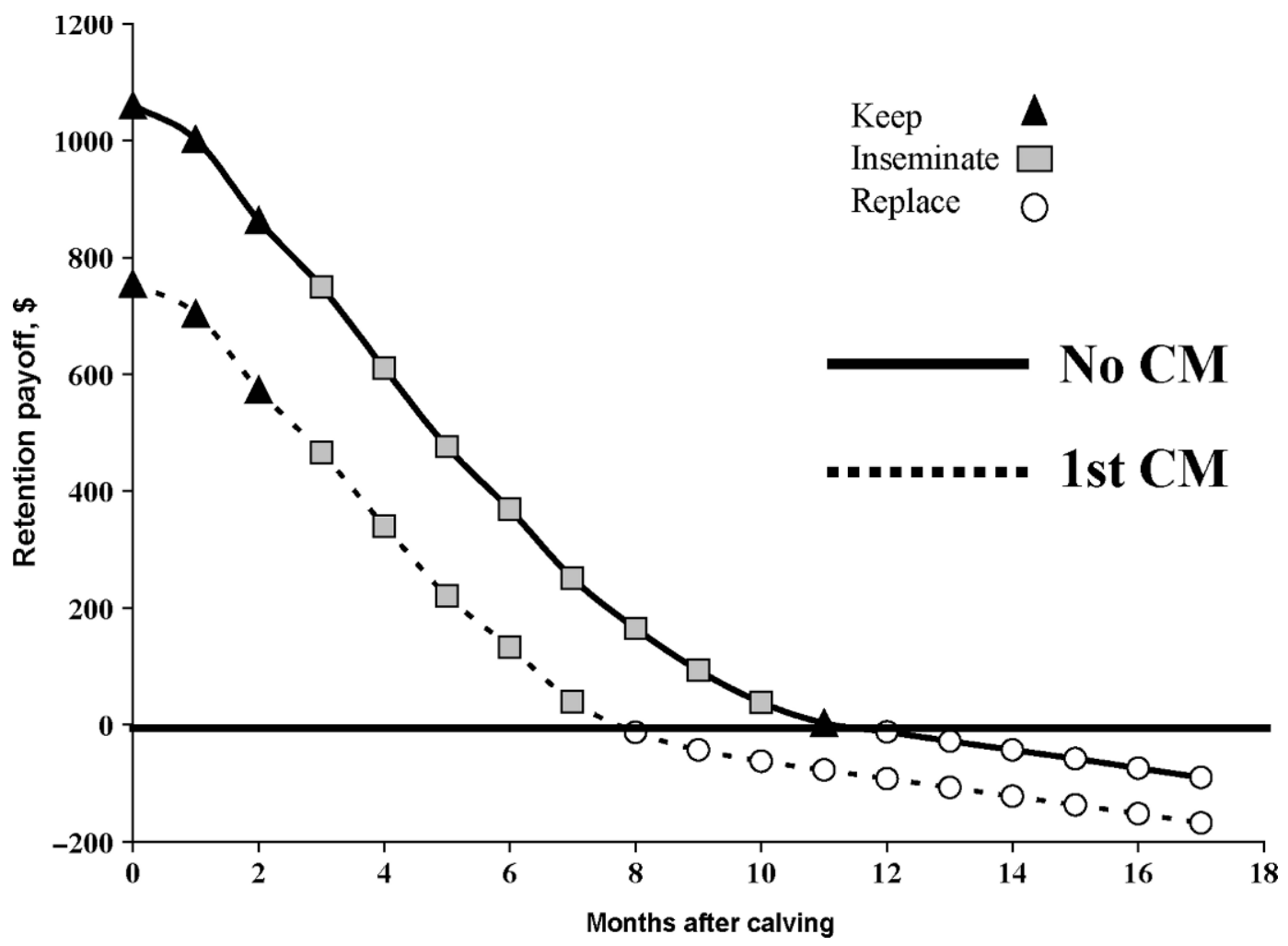

Figure 2. Retention payoffs under an optimal policy for a cow free of clinical mastitis (CM; solid line) and a cow that incurred CM in the same month (dotted line) by months after calving. Cows are in their third lactation with average lactation curves and without CM in the previous lactation. The cost of CM is equal to the difference between the retention payoffs of the healthy and CM diseased cows in the same month after calving.

milk yield. As an example, CM decreased the value of an average-producing, second-lactation cow $243 \mathrm{~d}$ after calving by $\$ 184[\$ 184-\$ 0(-\$ 22)]$ if not pregnant and by $\$ 330(\$ 531-\$ 201)$ if pregnant (Table 5). From this table, it can be seen that the cost of CM was similar if it was the first, second, or third case in the lactation, and the differences were generally too small to change the culling policy. The reduction of the RPO of an open, second-lactation cow $152 \mathrm{~d}$ after calving because of CM was $\$ 115[\$ 115-\$ 0(-\$ 3)], \$ 294(\$ 510-\$ 216)$, and $\$ 340$ (\$1,156 - \$816) for low-, average-, and high-milkyielding cows, respectively (Table 6). Cows with CM were recommended to be culled without treatment at different time points depending on their milk production: for an open, average-producing cow after $8 \mathrm{mo}$, for a low-producing cow after $5 \mathrm{mo}$, and for a high-producing cow after 10 mo. Temporary changes in the milk yield of the cow had only a subtle effect: for example,

Table 5. Expected retention payoff (in US dollars) of average-milk-producing open and pregnant cows in their second lactation, obtained by the insemination and replacement optimization model ${ }^{1}$

\begin{tabular}{|c|c|c|c|c|c|c|c|c|}
\hline \multirow[b]{3}{*}{ Item } & \multicolumn{8}{|c|}{ Days after calving } \\
\hline & \multicolumn{5}{|c|}{ Open cows } & \multicolumn{3}{|c|}{ Pregnant cows ${ }^{2}$} \\
\hline & 0 & 61 & 152 & 243 & 334 & 152 & 243 & 334 \\
\hline No CM & 1,237 & 912 & 510 & 184 & -12 & 796 & 531 & 285 \\
\hline First CM & 867 & 557 & 216 & -22 & -93 & 461 & 201 & -39 \\
\hline Second CM & $\mathrm{NA}^{3}$ & 595 & 230 & -15 & -93 & 471 & 211 & -29 \\
\hline Third CM & NA & 592 & 229 & -13 & -88 & 470 & 211 & -29 \\
\hline
\end{tabular}

${ }^{1}$ The decision to keep a clinical mastitis (CM) cow involves the cost of treatment.

${ }^{2}$ Cows became pregnant at this time point.

${ }^{3} \mathrm{NA}=$ not applicable. 
Table 6. Effect of milk production on expected retention payoff (in US dollars) of cows in their second lactation, obtained by the insemination and replacement optimization model ${ }^{1}$

\begin{tabular}{|c|c|c|c|c|c|}
\hline \multirow[b]{2}{*}{ Item } & \multicolumn{5}{|c|}{ Days after calving } \\
\hline & 0 & 61 & 152 & 243 & 334 \\
\hline \multicolumn{6}{|c|}{ Low milk yield ${ }^{2}$} \\
\hline No CM & 645 & 394 & 115 & 22 & -46 \\
\hline First CM & 403 & 194 & -3 & -81 & -126 \\
\hline \multicolumn{6}{|c|}{ Average milk yield } \\
\hline No CM & 1,237 & 912 & 510 & 184 & -12 \\
\hline First CM & 867 & 557 & 216 & -22 & -93 \\
\hline \multicolumn{6}{|c|}{ High milk yield ${ }^{3}$} \\
\hline No CM & 2,038 & 1,655 & 1,156 & 634 & 31 \\
\hline First CM & 1,626 & 1,273 & 816 & 374 & -60 \\
\hline \multicolumn{6}{|c|}{ Temporary low milk yield ${ }^{4}$} \\
\hline No CM & $\mathrm{NA}^{5}$ & 810 & 409 & 104 & -34 \\
\hline First CM & NA & 471 & 121 & -70 & -115 \\
\hline \multicolumn{6}{|c|}{ Average milk yield, $\mathrm{CM}$ in previous lactation } \\
\hline No CM & 1,011 & 761 & 375 & 94 & -43 \\
\hline First CM & 784 & 517 & 167 & -44 & -101 \\
\hline
\end{tabular}

${ }^{1}$ The decision to keep a cow with clinical mastitis (CM) involves the cost of treatment.

${ }^{2}$ Producing $5 \mathrm{~kg}$ of milk less per day throughout the cow's life span.

${ }^{3}$ Producing $5 \mathrm{~kg}$ of milk more per day throughout the cow's life span.

${ }^{4}$ Producing $4 \mathrm{~kg}$ of milk less per day than an average cow in the current month.

${ }^{5} \mathrm{NA}=$ not applicable.

in a cow that was temporarily lower producing $(4 \mathrm{~kg}$ per day) than an average cow, the CM cost $152 \mathrm{~d}$ after calving was $\$ 288$ (vs. $\$ 294$ if she remained at her current level). From Table 6, it can be seen that if a cow experienced CM in her previous lactation, she had an RPO in the current lactation that was approximately $\$ 200$ lower than a cow that stayed CM free in the previous lactation (in an average-producing cow and in the first few months of the lactation).

\section{DISCUSSION}

The objectives of this study were to estimate CMassociated costs and the dependence of these costs on cow- and herd-related factors. The average cost of a CM case in our study herds was $\$ 179$. It was composed of $\$ 115$ due to milk loss, $\$ 14$ due to increased mortality, and $\$ 50$ due to treatment-associated costs. In the basic scenario, $92 \%$ of the CM cases were recommended to be treated. The estimated cost of CM was highly dependent on cow traits (range: $\$ 3$ to $\$ 403$ ). The cost of a CM case was higher with increased milk price. The cost per episode of CM was affected little by a $20 \%$ change in replacement cost or pregnancy rate; however, these changes influenced the CM incidence, thereby changing CM costs at the herd level.

The values calculated here are relevant for the structure, parameters, and prices used. As underlined by Seegers et al. (2003), any mastitis cost estimation in a herd is, per se, of low external validity. Despite this, it is interesting that the 2 previously published dynamic models addressing CM estimated similar costs. Houben et al. (1994), using DP, estimated the loss per cow in the herd because of $\mathrm{CM}$ at $\$ 83$, with an incidence of 36.5 cases per 100 cow years. Østergaard et al. (2005), using dynamic simulation, estimated this cost at $\$ 90$, with an incidence of $42 \mathrm{CM}$ cases per 100 cow years (using a higher milk price than used in our basic scenario). Our estimate was $\$ 71$, with an incidence of 39.7 $\mathrm{CM}$ cases per 100 cow years. It is of note that we used data from farms that used a J5 vaccine, which has been shown to reduce the milk loss associated with gramnegative CM (Wilson et al., 2007).

The high dependence of disease cost on individual cow characteristics should not come as a surprise, although it has rarely been documented before (Seegers et al., 2003). Mastitis affecting a cow that should be replaced anyway has a low cost (only the increased mortality risk comes into play). The highest mastitis cost is associated with cows of high future expected income. Treatment of such cows can be justified even with high treatment costs. The average milk loss per $\mathrm{CM}$ case calculated by dynamic models is therefore less than that attributed to traditional static models. In fact, static models that add milk loss, increased culling costs, and treatment costs to all CM cases are actually more than double-counting costs: not all cows will experience the full estimated milk loss associated with CM, the increased culling is to a large extent a voluntary 
decision of the farmer, and not all cows with $\mathrm{CM}$ will even incur treatment costs.

The cost of CM is dependent on exogenous factors. A higher milk price is associated with a higher CM cost. This is because the value of the milk loss associated with $\mathrm{CM}$ has a higher monetary value. A lower replacement heifer price changed the cost per CM case only slightly, but the effect of $\mathrm{CM}$ on whole-herd profitability decreased because the incidence of $\mathrm{CM}$ was reduced substantially through a higher replacement rate (which results in having more young cows and fewer cows with previous CM cases, thus yielding a herd with lower CM risk). The effect of fertility on $\mathrm{CM}$ incidence might be less intuitive: higher pregnancy rate resulted in higher $\mathrm{CM}$ incidence. This is because a higher pregnancy rate means a greater chance of a cow surviving in the herd. Cows with high expected milk yield are more valuable under these conditions and are therefore recommended to be treated and kept in the herd despite having CM (with the result of fewer young cows and more cows with previous $\mathrm{CM}$ cases).

As in every model, the one developed here is a simplification of the real world. It was targeted for CM cost evaluation. A detailed representation of the varying costs of keeping a cow throughout her life span and a decreasing marginal feed efficiency (without the cost of keeping the cow in the herd) for high-producing cows was not modeled. This bonus for high-milk-yielding cows is somewhat compensated for by not considering a higher pregnancy value for cows with high permanent potential (because their offspring will have higher value). We did not model seasonality and milk component variations, nor did we model the exact shape of the lactation curves for very long lactations (beyond 18 mo). Addressing such issues was outside the scope of our objectives and might confound CM effects. Other model assumptions that are potentially violated in individual cases are an integral part of the DP framework. To name two, it is assumed that the farmer has total and perfect information on cow traits. In reality, this information is sometimes partial, or it is assumed that a replacement heifer immediately enters the milking herd after a cow replacement, but such a replacement can be delayed because such heifers are not readily available. We did not include in our model the effect of $\mathrm{CM}$ on fertility, so the results here are an underestimate. We are currently studying this effect in a larger scale study that is addressing bacteria-specific CM. A possible scenario, namely, the possibility of keeping a CM cow without treating her, was not modeled here. To have such a model, detailed information about the effect of omitting treatment of CM cows is needed. This information was not available to us.
Dynamic programming models such as ours are difficult to validate, and methods to validate these models are desirable (Seegers et al., 2003). In this respect, although it can be seen as merely a nonrefutable aspect, it is interesting to note that our model gave the same whole-herd profitability, culling rates, and elasticity of these parameters as the model developed by De Vries (2006). This was in spite of the differences between these 2 models in their structure (the De Vries model is not hierarchical and uses only value iteration), in the way milk yield is modeled (we used a linear decline of milk yield after peak production instead of a diphasic production function), in fertility modeling (abortion was not considered in our model), and in the culling rates for reasons unrelated to the model (mainly because CM was part of involuntary culling in the De Vries model). The simulated herd figures (e.g., age distribution, CM rates, percentage of cows replaced with $\mathrm{CM}$, and lactation lengths) following the optimal calculated replacement and insemination policy were also in agreement with the figures of the actual study herds. This is an indicator that the farmers in our study herds followed intuitively (at least in general) the best economic policy regarding breeding and culling decisions. In that case, our estimates of CM cost computed from an optimization model are reasonable approximations of the actual cost on well-managed farms.

Because our program enables editing parameters before actual model building, the same model can be used to calculate disease costs under other dairy parameters. The model developed here is not restricted to the investigation of mastitis economics. Similar diseases, such as lameness, can be evaluated within the same model with necessary parameter changes. For the estimation of calving disease costs, an even simpler model would be adequate (because a calving disease occurs only once per lactation and in the same time period for all cows affected).

Dynamic models such as the one presented here have the potential to become a useful decision aid tool in disease management, because the results are expressed not only as a recommended policy, but also as opportunity costs. By combining model results with additional factors (such as information about SCC, an individual cow's estimated beef price, etc.), real-time quantitative decisions are possible. To achieve a well-informed individual cow decision, a more detailed representation of the milk yield of the cow would be useful. The current model is designed for whole-herd CM cost estimation and whole-herd dynamics. It is therefore more useful for evaluating the average cost of a disease on a farm, or the cost-benefit of applying preventive measurements such as vaccination. 


\section{ACKNOWLEDGMENTS}

The USDA (Cooperative State Research, Education, and Extension Service, Washington, DC) Award No. 2005-35204-15714 provided funding for this study. The authors want to thank Anders Kristensen for providing his MLHMP software and for his valuable suggestions.

\section{REFERENCES}

Bar, D. 2007. Cost of generic clinical mastitis in dairy cows. PhD Thesis. Cornell University, Ithaca, NY.

Bar, D., Y. T. Gröhn, G. Bennett, R. N. González, J. A. Hertl, H. F. Schulte, L. W. Tauer, F. L. Welcome, and Y. H. Schukken. 2007. Effect of repeated episodes of generic clinical mastitis on milk yield in dairy cows. J. Dairy Sci. 90:4643-4653.

De Vries, A. 2006. Economic value of pregnancy in dairy cattle. J. Dairy Sci. 89:3876-3885.

Gröhn, Y. T., R. N. González, D. J. Wilson, J. A. Hertl, G. J. Bennett, H. F. Schulte, and Y. H. Schukken. 2005. Effect of pathogenspecific clinical mastitis on herd life in two New York State dairy farms. Prev. Vet. Med. 71:105-125.

Gröhn, Y. T., D. J. Wilson, R. N. González, J. A. Hertl, H. F. Schulte, G. J. Bennett, and Y. H. Schukken. 2004. Effect of pathogenspecific clinical mastitis on milk yield in dairy cows. J. Dairy Sci. 87:3358-3374.

Houben, E. H. P., R. B. M. Huirne, A. A. Dijkhuizen, and A. R. Kristensen. 1994. Optimal replacement of mastitic cows deter- mined by a hierarchical Markov process. J. Dairy Sci. 77:29752993.

Kristensen, A. R. 2003. A general software system for Markov decision processes in herd management applications. Comput. Electron. Agric. 38:199-215.

Kristensen, A. R., and T. A. Sollested. 2004. A sow replacement model using Bayesian updating in a three-level hierarchic Markov process. II. Optimization model. Livest. Prod. Sci. 87:25-36.

Makovec, J. A., and P. L. Ruegg. 2003. Results of milk samples submitted for microbiological examination in Wisconsin from 1994 to 2001. J. Dairy Sci. 86:3466-3472.

Nielsen, B. K., A. R. Kristensen, and S. M. Thamsborg. 2004. Optimal decisions in organic steer production-A model including winter feed level, grazing strategy and slaughtering policy. Livest. Prod. Sci. 88:239-250.

Østergaard, S., M. G. G. Chagunda, N. C. Friggens, T. W. Bennedsgaard, and I. C. Klaas. 2005. A stochastic model simulating pathogen-specific mastitis control in a dairy herd. J. Dairy Sci. 88:4243-4257.

Seegers, H., C. Fourichon, and F. Beaudeau. 2003. Production effects related to mastitis and mastitis economics in dairy cattle herds. Vet. Res. 34:475-491.

Wilson, D. J., B. A. Mallard, J. L. Burton, Y. H. Schukken, and Y. T. Gröhn. 2007. Milk and serum J5-specific antibody responses, milk production change, and clinical effects following intramammary Escherichia coli challenge for J5 vaccinate and control cows. Clin Vaccine Immunol. 14:693-699.

Yalcin, C., and A. W. Stott. 2000. Dynamic programming to investigate financial impacts of mastitis control decisions in milk production systems. J. Dairy Res. 67:515-528. 